\title{
GABA Metabolism and Transport: Effects on Synaptic Efficacy
}

\author{
Fabian C. Roth and Andreas Draguhn \\ Institute of Physiology and Pathophysiology, University of Heidelberg, 69120 Heidelberg, Germany \\ Correspondence should be addressed to Andreas Draguhn, andreas.draguhn@physiologie.uni-heidelberg.de
}

Received 14 November 2011; Accepted 19 December 2011

Academic Editor: Dirk Bucher

Copyright (C) 2012 F. C. Roth and A. Draguhn. This is an open access article distributed under the Creative Commons Attribution License, which permits unrestricted use, distribution, and reproduction in any medium, provided the original work is properly cited.

\begin{abstract}
GABAergic inhibition is an important regulator of excitability in neuronal networks. In addition, inhibitory synaptic signals contribute crucially to the organization of spatiotemporal patterns of network activity, especially during coherent oscillations. In order to maintain stable network states, the release of GABA by interneurons must be plastic in timing and amount. This homeostatic regulation is achieved by several pre- and postsynaptic mechanisms and is triggered by various activity-dependent local signals such as excitatory input or ambient levels of neurotransmitters. Here, we review findings on the availability of GABA for release at presynaptic terminals of interneurons. Presynaptic GABA content seems to be an important determinant of inhibitory efficacy and can be differentially regulated by changing synthesis, transport, and degradation of GABA or related molecules. We will discuss the functional impact of such regulations on neuronal network patterns and, finally, point towards pharmacological approaches targeting these processes.
\end{abstract}

\section{Introduction}

Activity within neuronal networks is contained between the extremes of complete silence and exceeding neuronal discharges. This general statement may seem intuitively right but has severe and nontrivial consequences for the function of neuronal networks. Several theoretical arguments and experimental findings support the notion that specific mechanisms secure a limited mean level of activity. Information content within neuronal networks is maximal under conditions of sparse coding, which means that only a minority of all local neurons is activated above threshold [1]. Furthermore, neurons are severely damaged by both extremes, that is, prolonged inactivity [2-5] or severe hyperactivity during epileptic seizures [6].

Many different mechanisms contribute to regulation of overall neuronal activity, including intrinsic neuronal properties $[7,8]$ and energy metabolism $[9,10]$. At the core of homeostasis, however, is the interplay between synaptic excitation and inhibition (Figure 1). All neuronal circuits of higher animals contain excitatory and inhibitory transmitter systems forming intense feed-forward and feedback connections $[11,12]$. The functional architecture of such networks can already explain homeostatic regulation of activity to a certain degree, and excitatory feedback loops tend to build up activity, which is counterbalanced by dampening actions of inhibitory feedback connections. A further element of cortical and subcortical microcircuits is inhibition of inhibitory neurons, resulting in a net excitation of downstream target cells. This mechanism may serve further functions in synchronizing neuronal activity and can be mediated by specialized interneurons [13]. In contrast, interactions between inhibitory neurons may also desynchronize neurons as, for example, Renshaw cells in the spinal cord $[14,15]$. This mechanism may serve to reduce fatigue of muscle fibers.

It should be noted that inhibitory neurons are not only important for balancing excitation. In several circuits, inhibitory neurons function as projection cells, rather than interneurons. For example, major projections within the basal ganglia and reticular nucleus of the thalamus and of the cerebellum are formed by GABAergic neurons [16-18]. In such networks, activity-dependent modulation of inhibition may have specific effects beyond balancing excitation, for example, the generation of specific physiological or pathological oscillation pattern [19]. 


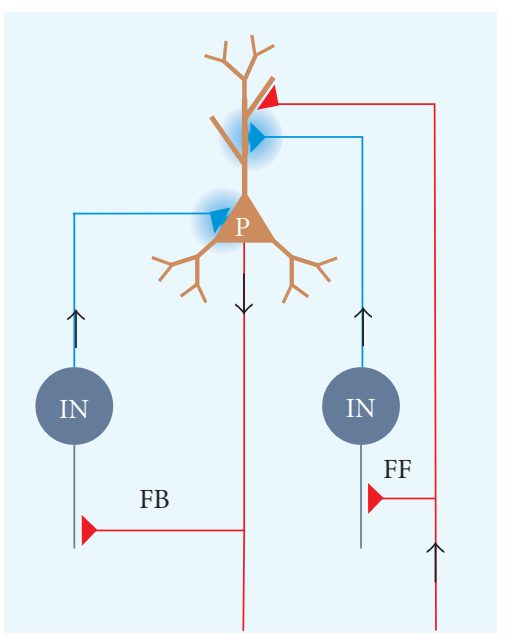

FIGURE 1: Local inhibitory connections of cortical networks. Note the efferent and afferent connections indicated by arrows. In red, connections indicate glutamatergic excitation and blue connections GABAergic inhibition. Brown soma indicates an excitatory pyramidal cell $(\mathrm{P})$, and blue-grey somata show inhibitory interneurons (INs). The left interneuron is integrated into a feedback inhibition loop, (FB) while the right interneuron shows feed-forward inhibition (FF). Differential targeting by the interneurons to the soma or dendrite points towards possible layer-specific actions of inhibition. Note that GABA released at the right synapse may, eventually, spill over to the neighbouring glutamatergic synapse. The global light blue staining indicates background GABA concentration that mediates tonic inhibition depending on local synaptic activity.

Homeostasis between excitation and inhibition cannot be reduced to a simple rule of network wiring. Recent evidence shows that inhibition has multiple specific functions within neuronal networks, far beyond a simple "break" $[20,21]$. Moreover, inhibitory strength is not constant but must adapt to dynamically changing patterns and degrees of network activity. It does therefore not come as a surprise that recent work has elucidated multiple mechanisms of plasticity at inhibitory synapses [4, 22-24]. An important subset of these mechanisms mediates homeostatic plasticity, that is, adaptation of inhibitory efficacy to the overall activity within a local network. Indeed, several lines of evidence suggest that GABAergic efficacy is upregulated in hyperactive networks [25-29] and downregulated under conditions of reduced activity $[5,30,31]$.

Such homeostatic reactions can, in principle, be mediated by multiple pre- and postsynaptic mechanisms. A particularly important regulatory system, however, is the concentration of the main mammalian inhibitory transmitter GABA ( $\gamma$-aminobutyric acid). This paper shall summarize the molecular elements and functional mechanisms involved in regulation of GABA concentration within vesicles, cells, and in the extracellular space. We will quote experimental evidence indicating that GABA is homeostatically regulated during physiological and pathological changes of network activity. Finally, we will consider how molecular determinants of GABA concentration can be targeted by drugs for pharmacological therapy of neurological or psychiatric diseases.

\section{Organization of GABAergic Synapses}

In the mammalian CNS, inhibition is mediated by the amino acids GABA and glycine. The GABAergic system has been intensely explored during recent years and will therefore be the main focus of this paper. As a starting point, we will briefly summarize the main functional and structural elements of GABAergic synapses.

GABA binds to two different types of receptors-ion channels and metabotropic receptors. GABA-gated ion channels are selectively permeable for chloride and bicarbonate and have reversal potentials close to $\mathrm{Cl}^{-}$equilibrium $\left(\mathrm{E}_{\mathrm{Cl}}\right)$. These channels are mostly termed $\mathrm{GABA}_{\mathrm{A}}$ receptors, but a molecularly and pharmacologically distinguishable subset has also been termed $\mathrm{GABA}_{\mathrm{C}}$ receptors until recently, as discussed by Olsen and Seighart [32]. In most cases, the increase in chloride (and bicarbonate) conductance resulting from activation of ionotropic GABA receptors causes inhibition of the respective neuron, that is, decreased probability of action potential generation. This is easy to understand in cases where $\mathrm{E}_{\mathrm{Cl}}$ is more negative than the membrane potential, such that opening of $\mathrm{GABA}_{\mathrm{A}}$ receptors causes hyperpolarisation and enhances the distance between membrane potential and action potential threshold. However, inhibition can also be mediated by more complex biophysical mechanisms, for example, shunting of the local membrane resistance, which can also counteract excitatory inputs. Even depolarizing actions of GABA can, in certain cases, be inhibitory [3335]. Conversely, excitatory actions of GABA may occur in specific situations, including early developmental stages [3639] and maladaptive processes, for example, in chronic epilepsy $[40,41]$. The occurrence of depolarizing GABA responses under physiological conditions is presently subject to some controversy $[39,42]$. GABA $\mathrm{B}_{\mathrm{B}}$ receptors, in contrast, are members of the family of G-protein-coupled proteins [43] and react to GABA binding by dimerisation [44] and activation of downstream signal cascades. These include decreased probability of transmitter release and increase in pre- and postsynaptic $\mathrm{K}^{+}$conductance $[45,46]$.

A complete survey of GABAergic mechanisms at the molecular, cellular, and network level is far beyond the scope of this paper. Rather, we will highlight three principles of organization of GABA-mediated inhibition that are particularly important for understanding how GABA regulates network activity. The molecular constituents involved in regulation of inhibitory strength are detailed below.

(i) GABA regulates excitability on different temporal and spatial scales. One important mechanism is tonic inhibition, which results from diffusely distributed GABA within the extracellular space of networks, thereby reducing excitability of all local neurons (Figure 1). Recent evidence has shown that tonic inhibition is of major importance for reducing firing probability of defined types of neurons within cortical networks [24, 47-49]. In some cells, this 
mechanism accounts for more than $50 \%$ of GABAinduced chloride conductance [50]. Background levels of GABA in neuronal tissue have been estimated to reach high-nanomolar to low-micromolar concentrations $[51,52]$. In good accordance with this relatively low concentration, extrasynaptic GABA receptors have particularly high agonist affinity [47, 53, 54]. At the other extreme, phasic inhibition is mediated by locally and temporally restricted release of GABA from synaptic terminals. This action causes a short, exponentially rising and falling of the postsynaptic chloride conductance which can last from few to tens of milliseconds $[50,55]$. Most GABAergic neurons seem to form such specific synaptic sites for phasic inhibition, but recent evidence indicates that there are also specialized interneurons which release GABA for tonic inhibition [56-60]. Tonic inhibition depends on special GABA receptors, which can be selectively modulated by drugs, for example, neurosteroids. These specific receptor isoforms may be important in the pathophysiology of depression [61] and withdrawal symptoms [62]. Such examples of receptor heterogeneity may well open new therapeutic chances.

(ii) GABAergic interneurons are diverse. Work on different networks has revealed an unprecedented multitude of different GABAergic neurons which are classified by their somatic location, dendritic branching, axonal projection, afferent synaptic integration, intrinsic membrane properties, and expression of molecular markers, especially neuromodulatory peptides and calcium-binding proteins. Extensive classification systems have been established for different circuits, for example, for the rodent neocortex $[63,64]$ and the hippocampus [13, 65]. Moreover, introducing the juxtacellular recording technique has enabled recordings from individual interneurons in behaving animals and subsequent in-depth structural analysis [66]. These data have shown that different types of interneurons are specialized to organize different patterns of network activity [67].

(iii) In accordance with the heterogeneity and functional specialization of different cell types, experiments and computer modelling have revealed important functions of "inhibitory" interneurons in networks beyond merely dampening excitation. Interneurons turned out to play a key role in organizing the spatiotemporal activity of local networks, especially during synchronous network oscillations [68-73]. Complementary neuroanatomical work has highlighted the structural basis for this function: interneurons have highly divergent axonal projections, cell typespecific afferent and efferent connectivity, and synchronizing mutual connections. All these properties favour synchronous rhythmic inhibition of large populations of principal cells $[13,69,71,74-76]$. It should be noted that the connections between excitatory projection cells and inhibitory interneurons provide an automatic homeostatic mechanisms at the network level. Feed forward or feedback inhibition is driven by excitatory inputs or outputs, respectively, from remote or local excitatory neurons. This mechanism does automatically recruit inhibitory neurons in an activity-dependent manner and, hence, balance local activity (Figure 1).

\section{Key Molecules for GABAergic Signalling}

The molecular organization of synapses is highly complex, and a complete review would be beyond the scope of this paper. We will restrict our remarks to some families of molecules that are crucial for understanding homeostatic regulation of GABA concentration (Figure 2).

Like many other neurotransmitters, GABA acts on ionotropic as well as metabotropic ion channels. GABA $A_{A}$ receptors are pentameric ion channels composed out of a large variety of 19 homologous subunits [32, 77, 78]. Work during the past decades has elucidated numerous functional differences between molecular subtypes of $\mathrm{GABA}_{\mathrm{A}} \mathrm{R}$, including different expression patterns, differential modulation by benzodiazepines, neurosteroids and $\mathrm{Zn}^{2+}$, different compartmentalization within neurons, and different agonist affinity $[32,54,79]$. The latter properties are of special interest with respect to GABA concentration. $\mathrm{GABA}_{\mathrm{A}} \mathrm{Rs}$ with low agonist affinity appear to be clustered at postsynaptic sites, whereas receptors with high affinity are mostly found extrasynaptically $[47,48]$. The underlying sorting mechanisms are partially known and involve specific subsynaptic sorting signals within the gamma subunit and interactions with postsynaptic scaffolding proteins like gephyrin and collybistin [80-83]. Extrasynaptic receptors, in contrast, are formed by subunits mediating high agonist affinity including $\alpha 4, \alpha 6$, and $\delta$ subunits [32, 47]. This distinction reflects the different concentrations of GABA at both sites: whereas synaptically released GABA may reach transient concentrations of $\sim 1.5-3 \mathrm{mM}[84,85]$, extrasynaptic transmitter concentration has been estimated to lie in the low micromolar range of about $0.2-2.5 \mu \mathrm{M}[47,51,52,86]$. As mentioned above, these apparently low "background" concentrations of GABA may be very efficient in regulating excitability [4750]. An additional distinct location of $\mathrm{GABA}_{\mathrm{A}}$ receptors is the presynaptic terminal itself. GABAergic auto- or heteroreceptors have been described at the axon terminals of various neurons, including spinal cord afferents [87], hippocampal mossy fibres [88], Schaffer collaterals [89], cerebellar interneurons [90], and pituitary terminals [91]. The effects of such receptors are diverse. Depending on the GABA-induced change in membrane potential and local membrane resistance, presynaptic $\mathrm{GABA}_{\mathrm{A}}$ receptors may increase or decrease transmitter release [92].

$\mathrm{GABA}_{\mathrm{B}}$ receptors, on the other hand, are G-proteincoupled transmembrane molecules which are activated by low concentrations of GABA and form dimers which then trigger secondary signalling cascades [43-45]. At presynaptic terminals, activation of $\mathrm{GABA}_{\mathrm{B}} \mathrm{Rs}$ reduces $\mathrm{GABA}$ release, forming the typical negative feedback loop of autoreceptormediated synaptic gain control. $\mathrm{GABA}_{\mathrm{B}}$ receptors are also 


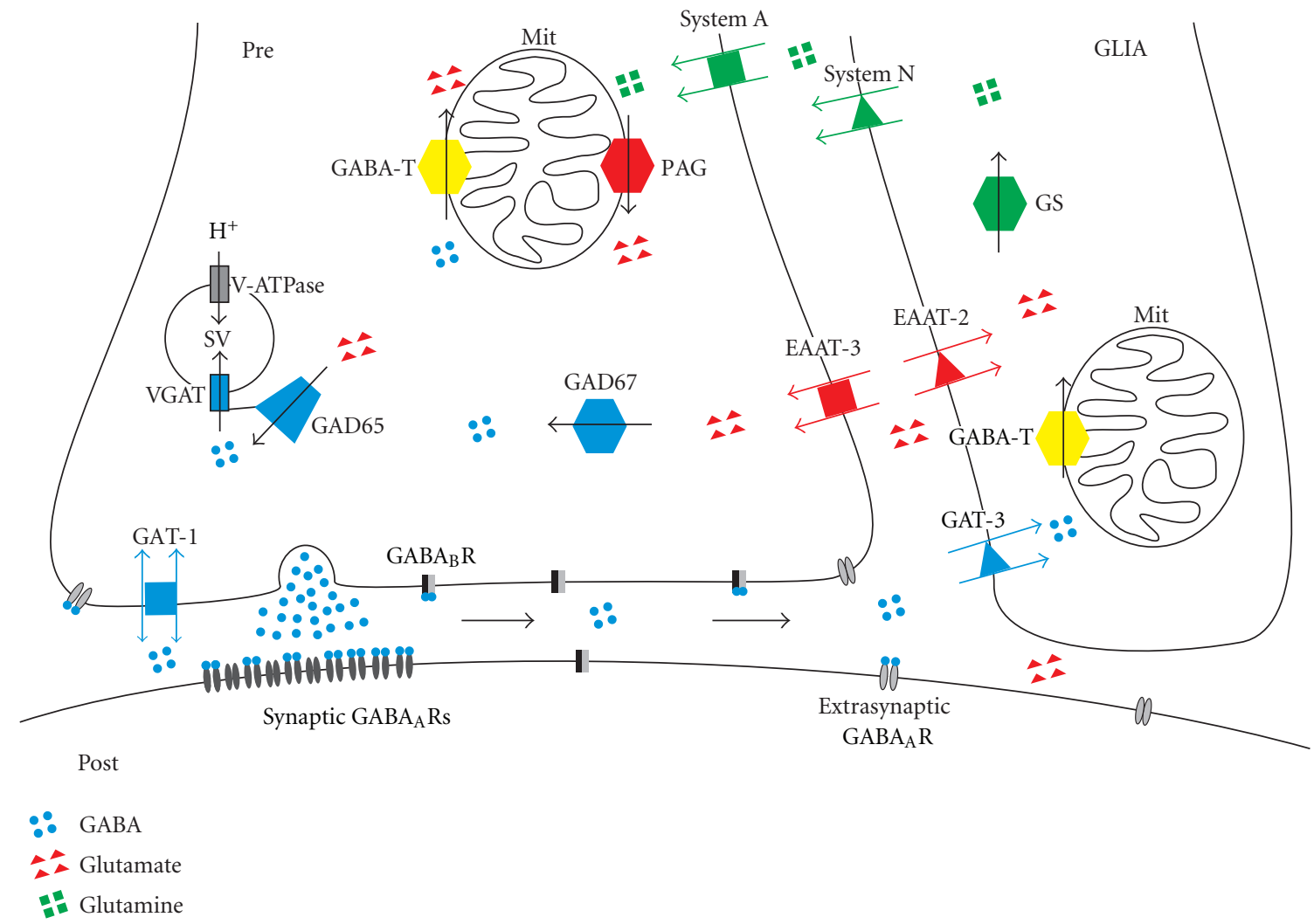

FIGURE 2: Schematic drawing of transmitter release, transport, and synthesis at a GABAergic synaptic terminal. The axonal ending of an inhibitory interneuron (PRE) is drawn on the left, a glial cell (GLIA) on the right. Bottom structure indicates postsynaptic membrane of a target cell (POST), for example, a pyramidal neuron. Transporters are marked by flanking arrows, and synthesizing or degrading enzymes are marked by a centred arrow. Transporters are colour matched to substrates: GABA is shown as blue particles, glutamate in red, and glutamine in green. GS: glutamine synthetase, Mit: mitochondrion, PAG: phosphate-activated glutaminase, SV: synaptic vesicle, and VATPase: vacuolar-type $\mathrm{H}^{+}$-ATPase. For other abbreviations, see the main text.

present at glutamatergic terminals, pointing towards regular spillover of GABA from inhibitory to excitatory synapses

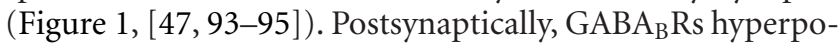
larize and inhibit neurons by activating inwardly rectifying $\mathrm{K}_{\mathrm{IR}}$ channels, giving rise to the "slow" or "late" phase of inhibition that follows fast, $\mathrm{GABA}_{\mathrm{A}} \mathrm{R}$-mediated effects and lasts several hundred milliseconds [96]. Furthermore, GABA receptors can also mediate tonic inhibition, exerting negative control on overall network activity [97].

\section{GABA Transport and Synthesis}

While GABA receptors act as "detectors" of local GABA concentration, the regulation of GABA itself is achieved by several specialized molecular mechanisms mediating transport, sequestration, synthesis, and the degradation of GABA. We will briefly address each class of molecules involved in these processes.

Membrane-bound GABA transporters move GABA across the cell membrane (Figure 2). The direction and efficacy of this $\mathrm{Na}^{+}$-coupled transport results from the driving electrochemical gradient and is directed inwardly in most situations $[98,99]$. However, upon strong depolarization or altered ion homeostasis, GABA transporters can also reverse direction. This mechanism leads to nonvesicular release of GABA which may be of special importance in pathophysiological situations $[60,100,101]$. GABA transporters appear in four different isoforms with affinities around $7 \mu \mathrm{M}$ for rat GAT-1, $8 \mu \mathrm{M}$ for rat GAT-2, $12 \mu \mathrm{M}$ for rat GAT-3, and $93 \mu \mathrm{M}$ for rat BGT-1 [102-106]. Terminology of GABA transporters is not fully compatible between rats and mice [107]. In the following, we use the abbreviations for rat GABA transporters where ratGAT-1 = mouseGAT1; ratGAT2 = mouse GAT3; ratGAT-3 = mouseGAT4; ratBGT-1 = mouse GAT2. GABA transporters are differentially expressed in the CNS. As a global rule, GAT-1 is the prevailing neuronal isoform in the rodent brain, and GAT-3 is strongly expressed in glial cells [108-110]. Expression of different GAT isoforms is, however, overlapping, so that selective modulation of one isoform will always affect more than one cell type. It might therefore turn out impossible to achieve a strictly selective block of glial or neuronal GABA uptake with conventional pharmacological tools.

An alternative pathway for enriching GABA in presynaptic terminals is transmitter synthesis from glutamate. Similar to GAT-1/3, there are membrane-bound glutamate transporter molecules at presynaptic terminals of inhibitory interneurons, namely EAAC1 (also called EAAT3) 
[111-113]. Moreover, neurons can synthesize glutamate from glutamine which can also be taken up by specialized transporters (see below) [114, 115]. GABAergic neurons express both mature isoforms of glutamate decarboxylase, GAD65 and GAD67 [116, 117], that convert the excitatory amino acid into GABA. The smaller isoform GAD65 is directly associated to presynaptic vesicles, indicating that glutamate, once present in the presynaptic cytosol, can be rapidly used for vesicular enrichment of GABA. Indeed, there are direct protein interactions between GAD65 and the vesicular GABA transporter VGAT (= VIAAT, vesicular inhibitory amino acid transporter), suggesting that conversion of glutamate into GABA and subsequent vesicular uptake of the transmitter may be strongly coupled processes [118].

More recently, glutamine has gained interest as an alternative source of GABA. The amino acid glutamine has long been known as the immediate precursor for glutamate. In the extracellular space, glutamine may reach concentrations of hundreds of $\mu \mathrm{M}[119,120]$. Enrichment of glutamate in excitatory central neurons involves uptake through specific glutamate transporters by glia cells, conversion into glutamine, export via "system N" glutamine transporters, uptake into neurons by "system A" glutamine transporters, and conversion into glutamate $[121,122]$. There is increasing evidence for a similar role of this glutamate/glutamine cycle in GABA synthesis. Indeed, inhibitory interneurons in the hippocampus express the system A transporter SNAT1 [115], but not SNAT2 [123]. Recordings of epileptiform activity in rodent brain slices in vitro have revealed functional evidence for boosting of inhibition by glutamine via this mechanism [124-127]. Using high-resolution recordings of miniature IPSCs in conjunction with pharmacological manipulation of glutamine levels and glutamine transport, these studies showed that glutamine can serve as a source for GABA, especially under conditions of increased synaptic activity. More recent evidence from rat hippocampal slices showed that the contribution of glutamine to vesicular GABA content is more pronounced in immature tissue, and that glutamine forms a constitutive source of vesicular GABA in immature hippocampal synapses on CA1 pyramidal cells. At later stages, the functional importance seems to be restricted to periods of enhanced synaptic activity [128]. This loss of function for constitutive GABA release under resting conditions goes along with an age-dependent decline in expression of SNAT1, both absolutely and in relation to the GABA-synthesizing enzyme GAD65.

\section{Sequestration and Degradation of GABA}

Within presynaptic terminals of GABAergic neurons, GABA is enriched in vesicles by the vesicular inhibitory amino acid transporter $($ VGAT $=$ VIAAT $)$. This protein is embedded in the vesicular membrane and uses the electrochemical gradient for $\mathrm{H}^{+}$to shuffle GABA into small synaptic vesicles [129-133]. Additionally, chloride gradients between vesicle lumen and presynaptic cytosol may contribute to the vesicular loading of GABA $[129,131]$. Interestingly, VGAT processes both major mammalian inhibitory transmitters,
GABA and glycine. This is a prerequisite for the observed GABAergic/glycinergic cotransmission by single vesicles in the spinal cord [134]. Modelling studies and biochemical data suggest that vesicular GABA uptake may achieve an 1000 -fold increase of the transmitter in vesicles as compared to the presynaptic cytosol [135]. On the other side, recent evidence suggests that GABAergic synaptic vesicles are leaky, implying generation of a dynamic equilibrium between accumulation and loss of GABA, given that there is enough time to reach such a steady state $[132,136]$. Taking this bidirectional transport into account, the "leaky bathtub" model of synaptic vesicles comes to rather low estimates of concentration gradients between cytosol and the inner vesicle space $[132,135,137]$.

Finally, GABA and $\alpha$-ketoglutarate can be transaminated, producing succinic semialdehyde and glutamate. The reaction is catalysed by GABA transaminase (GABA-T) which is present in mitochondria of glial cells and neurons [138140]. It is estimated that more than $90 \%$ of all GABA in the mammalian CNS is degraded in this way and contributes to energy metabolism in the tricarbonic acid cycle.

In summary, there are several different molecular pathways and compartments for enrichment, synthesis, and degradation of GABA (Figure 2). The resulting concentration of GABA in synaptic vesicles and in the extracellular space depends on the equilibrium between these mechanisms. It should be clearly stated that the absolute concentrations of GABA in the presynaptic cytosol, in vesicles, and in the extrasynaptic space are not known. The affinity constants of extrasynaptic GABA receptors may serve as a rough estimate of background concentrations $(0.2-2.5 \mu \mathrm{M})$ [86]. Direct measurements from rat cerebrospinal fluid yielded similar or slightly higher values which may be lower in humans [141].

The highly dynamic time course of transmitter concentration in the synaptic cleft, on the other hand, has been estimated based on experimental and theoretical work in different types of neurons. Peak concentrations may be as high as 0.3 to $3 \mathrm{mM}[85,142-147]$. The cytosolic GABA concentration is most difficult to estimate or measure, especially since most of the neuronal GABA pool is used for energy metabolism rather than for synaptic inhibition.

It should be explicitly stated that none of the above-given numbers has been directly measured. Indeed, our knowledge on local GABA concentrations in different compartments is far from sufficient. This is even more concerning when we take into account the enormous heterogeneity of neurons $[20,63,65]$, the different microarchitecture of different local circuits, and activity-dependent changes in GABA release and ionic homeostasis. A major challenge is the lack of quantitative data about key molecules and structures: How many GABA-uptake molecules are present at a given inhibitory synapse? What is their distribution with respect to the site of release? What is the precise extracellular volume at the synaptic cleft? How much GABA does go into glia cells and neurons, respectively? An important example for progress in this quantitative molecular approach to subcellular structure and function is the recent work on the vesicular proteasome by Takamori and colleagues [136]. 


\section{Regulation of (GABA) in Physiology and Pathophysiology}

Different lines of evidence support the view that the cellular and molecular mechanisms mentioned above make important contributions to homeostatic synaptic plasticity. This term covers changes of intrinsic and synaptic neuronal properties, which maintain the mean network activity within a determined range $[4,28]$. Taking into consideration that network states change rapidly with changes in vigilance and behavioural state $[148,149]$, this is a nontrivial task. Individual neurons can change their activity at least by a factor of $\sim 6$ in different network patterns [150]. Nevertheless, under normal conditions, networks do neither fall into complete silence, nor into pathological hyperactivity.

Inhibition plays a critical role in network homeostasis. Most circuits contain specialized inhibitory cells which are activated by external afferent excitatory inputs (feedforward inhibition) or by collaterals from efferent excitatory axons (feedback inhibition) as illustrated in Figure 1 [11]. These inhibitory control loops ensure that excitatory neurons are inhibited in an activity-dependent manner. It should be noted, however, that inhibitory interneurons are much more than a "brake" or "gain control." Recent evidence has revealed many other functions for these heterogeneous neurons: they are critical for organizing the complex spatial and temporal patterns of network oscillations [70, 71], selective gating of defined inputs or outputs [20], suppression of background activity [151], and precise timing of action potentials [67]. Corresponding with these specific functions, we are gaining increasing insight into the complexity of GABAergic signalling, diversity of interneurons, and plasticity of inhibitory synapses.

Notwithstanding these recent findings, however, inhibition does still have its traditional function, that is, limitation of neuronal activity. With respect to network homeostasis, this control function must adapt to changing degrees of activity in the local network. Several lines of evidence indicate that modulating GABA content of inhibitory interneurons is a key mechanism in this regulation process. For example, repetitive hyperactivity in the hippocampus of chronically epileptic rats causes upregulation of GADs, the key enzymes for production of GABA [29]. Conversely, the partial deafferentation of somatosensory cortex resulting from partial limb amputations leads to a downregulation of GABA, but not of GADs [30, 152]. These findings indicate that GABA levels are increased or decreased, respectively, in response to increasing or decreasing network activity. The underlying mechanisms are diverse with respect to time course and source of GABA.

Long-term changes in excitability, such as described above, require regulation of protein expression. Multiple studies from excitatory synapses show that changes in synaptic activity do indeed include lasting effects on protein synthesis and synaptic protein content $[153,154]$. The underlying mechanisms involve calcium signalling in dendrites and nuclei $[30,155]$. Much less is known about similar mechanisms in inhibitory interneurons. It would be of special importance to understand the activity-dependent regulation of key proteins such as GAD, VGAT, and others. Interestingly, BDNF (brain-derived neurotrophic factor) increases expression of GAD, indicating that neurotrophins are involved in inhibitory homeostatic plasticity. This would be well compatible with the general role of these molecules in activity-dependent plasticity [156]. Surprisingly, genes for inhibitory transmission can also be upregulated in excitatory, glutamatergic neurons following periods of enhanced activity. This intriguing finding suggests that excitatory neurons can adopt an active role in synaptic inhibition in certain situations. Such a "dual phenotype" has been clearly demonstrated in dentate granule cells, a major excitatory input cell type in the rodent hippocampus [157-159]. The axons of granule cells, called mossy fibres, form strong glutamatergic synapses on proximal dendrites of CA3 pyramidal cells and do also contact inhibitory interneurons in this region (an example of feedforward inhibition). Upon strong repetitive stimulation or following epileptic seizures, mossy fibres start expressing proteins needed for the production and vesicular storage of GABA. Electrophysiological measurements show that this GABAergic phenotype is indeed functional, giving rise to mixed excitatory and inhibitory potentials in CA3 pyramids. The GABAergic phenotype of mossy fibres seems to be more pronounced in the juvenile brain [157], consistent with the general principle of enhanced plasticity in immature neurons. While the dual phenotype of granule cells may be an extreme example, several observations indicate that similar activity-dependent changes in expression of GABAergic molecules affect the vesicular pool of GABA in typical inhibitory interneurons. For example, expression of VGAT is altered following ischemia or excitotoxic stimulation [160-162]. These changes go along with altered composition of the vesicular proteome, indicative of altered supply or release of GABAergic vesicles [163].

At a shorter time scale, GABA levels might be regulated by activity-dependent uptake of transmitter molecules. Experimental evidence for such changes came from direct injection of glutamate [164] or glutamine [124, 125] into hippocampal slices. Both approaches increased the amplitudes of miniature inhibitory postsynaptic currents (mIPSCs), indicating that the precursors had indeed been used to fuel the vesicular transmitter pool. Consistent with these findings, blocking membrane-bound transporters for glutamine, GABA, or glutamate can reduce the size of IPSCs $[128,162,165,166]$. The relative contribution of GABA, glutamate, or glutamine uptake to the vesicular GABA pool remains, however, unknown. It can be expected that the contribution of different transmitter transporters differs among neuronal subtypes, brain regions, and developmental stages $[128,167]$. However, due to the fast action of uptake molecules, it is well possible that homeostatic adaptations of intravesicular GABA concentration occur at time scales of few seconds. Strong activation of axons in the CA1 area of mouse hippocampal slices results in a rapid increase of mIPSC amplitudes, with onset time below $20 \mathrm{~s}$. This increase is dependent on uptake of glutamate and GABA, indicating that increased extracellular transmitter concentrations in active neuronal networks automatically provide more "fuel" 
to the pool of releasable GABA, thereby constituting a negative feedback loop [165].

We have already discussed that tonic activation of GABA receptors by ambient transmitter concentrations provides a major mechanism for regulation of excitability $[47,48,50]$. It may, therefore, well be that changes in GABA uptake, production, and release cause altered tonic inhibition, possibly mediated by specialized subtypes of interneurons [56]. Quantitative knowledge about the contribution of these mechanisms is still lacking. It is also unclear how much nonvesicular release of GABA by reverse transport contributes to ambient GABA concentration. Situations of hyperactivity may favour such release mechanisms by sustained depolarization and altered local ion homeostasis [59, $60,100,168]$.

\section{Pharmacological Use}

Enhancing GABAergic inhibition is useful for the treatment of several pathological situations, including chronic pain, sleep disorders, anxiety, and-most importantly-epilepsy. In accordance with the principles outlined above, several drugs have been developed which alter presynaptic GABA content. One approach is blocking GABA degradation by GABA transaminase (GABA-T), using the suicide inhibitor $\gamma$-vinyl-GABA (GVG). Indeed, this drug does increase GABA levels in the brain $[169,170]$ and has anticonvulsant efficacy $[171,172]$. Studies at the single cell level show that GVG increases miniature IPSC amplitude, consistent with a dynamic regulation of vesicular GABA concentration by the equilibrium between synthesis and degradation $[173,174]$. Clinical use of GVG is, however, limited due to pathological changes of retinal cells and resulting scotoma [175].

An alternative approach suited to enhance synaptic GABA levels is the redirection of GABA uptake from glia to neurons. In glial cells, most GABA is degraded and fed into energy metabolism [176]. In contrast, neuronal GABA uptake can recycle the amino acid for use as a transmitter. It would therefore be ideal to have glia-specific GABA uptake inhibitors. Unfortunately, the molecular distinction between glial and neuronal GABA uptake is not strict, although there is some bias for GAT-1 in neurons and GAT-3 in glia [108$110]$.

In summary, there is no doubt that changes in GABA concentration contribute significantly to network homeostasis in health and disease. More quantitative information about sources, compartmentalization, and local concentration of GABA is urgently needed, not at least in order to develop more specific drugs for reconstituting excitationinhibition balance in pathological situations.

\section{References}

[1] J. Wolfe, A. R. Houweling, and M. Brecht, "Sparse and powerful cortical spikes," Current Opinion in Neurobiology, vol. 20, no. 3, pp. 306-312, 2010.

[2] K. N. Hartman, S. K. Pal, J. Burrone, and V. N. Murthy, "Activity-dependent regulation of inhibitory synaptic transmission in hippocampal neurons," Nature Neuroscience, vol. 9, no. 5, pp. 642-649, 2006.

[3] E. Schonfeld-Dado and M. Segal, "Activity-dependent survival of neurons in culture: a model of slow neurodegeneration," Journal of Neural Transmission, vol. 116, no. 11, pp. 1363-1369, 2009.

[4] A. Maffei and G. G. Turrigiano, "Multiple modes of network homeostasis in visual cortical layer 2/3," Journal of Neuroscience, vol. 28, no. 17, pp. 4377-4384, 2008.

[5] V. Kilman, M. C. W. Van Rossum, and G. G. Turrigiano, "Activity deprivation reduces miniature IPSC amplitude by decreasing the number of postsynaptic $\mathrm{GABA}_{\mathrm{A}}$ receptors clustered at neocortical synapses," Journal of Neuroscience, vol. 22, no. 4, pp. 1328-1337, 2002.

[6] Y. Ben-Ari, "Cell death and synaptic reorganizations produced by seizures," Epilepsia, vol. 42, no. 3, pp. 5-7, 2001.

[7] J.P. Adelman, J. Maylie, and P. Sah, "Small-conductance $\mathrm{Ca}^{2+}$ activated $\mathrm{K}^{+}$channels: form and function," Annual Review of Physiology, vol. 74, pp. 245-269, 2012.

[8] A. Marty, "The physiological role of calcium-dependent channels," Trends in Neurosciences, vol. 12, no. 11, pp. 420424, 1989.

[9] M. O. Cunningham, D. D. Pervouchine, C. Racca et al., "Neuronal metabolism governs cortical network response state," Proceedings of the National Academy of Sciences of the United States of America, vol. 103, no. 14, pp. 5597-5601, 2006.

[10] C. Huchzermeyer, K. Albus, H. J. Gabriel et al., "Gamma oscillations and spontaneous network activity in the hippocampus are highly sensitive to decreases in $\mathrm{pO} 2$ and concomitant changes in mitochondrial redox state," Journal of Neuroscience, vol. 28, no. 5, pp. 1153-1162, 2008.

[11] H. Mohler, P. Malherbe, A. Draguhn, and J. G. Richards, " $\mathrm{GABA}_{\mathrm{A}}$-receptors: structural requirements and sites of gene expression in mammalian brain," Neurochemical Research, vol. 15, no. 2, pp. 199-207, 1990.

[12] M. Ferrante, M. Migliore, and G. A. Ascoli, "Feed-forward inhibition as a buffer of the neuronal input-output relation," Proceedings of the National Academy of Sciences of the United States of America, vol. 106, no. 42, pp. 18004-18009, 2009.

[13] T. F. Freund and G. Buzsáki, "Interneurons of the Hippocampus," Hippocampus, vol. 6, no. 4, pp. 347-470, 1996.

[14] M. G. Maltenfort, C. J. Heckman, and W. Z. Rymer, "Decorrelating actions of renshaw interneurons on the firing of spinal motoneurons within a motor nucleus: a simulation study," Journal of Neurophysiology, vol. 80, no. 1, pp. 309-323, 1998.

[15] F. J. Alvarez and R. E. W. Fyffe, "The continuing case for the Renshaw cell,” Journal of Physiology, vol. 584, no. 1, pp. 3145, 2007.

[16] J. M. Tepper, C. J. Wilson, and T. Koós, "Feedforward and feedback inhibition in neostriatal GABAergic spiny neurons," Brain Research Reviews, vol. 58, no. 2, pp. 272-281, 2008.

[17] A. Gonzalo-Ruiz and A. R. Lieberman, "GABAergic projections from the thalamic reticular nucleus to the anteroventral and anterodorsal thalamic nuclei of the rat," Journal of Chemical Neuroanatomy, vol. 9, no. 3, pp. 165-174, 1995.

[18] B. J. Fredette and E. Mugnaini, "The GABAergic cerebelloolivary projection in the rat," Anatomy and Embryology, vol. 184, no. 3, pp. 225-243, 1991.

[19] A. Schnitzler and J. Gross, "Normal and pathological oscillatory communication in the brain," Nature Reviews Neuroscience, vol. 6, no. 4, pp. 285-296, 2005. 
[20] T. Klausberger and P. Somogyi, "Neuronal diversity and temporal dynamics: the unity of hippocampal circuit operations," Science, vol. 321, no. 5885, pp. 53-57, 2008.

[21] G. Birke and A. Draguhn, "No simple brake the complex functions of inhibitory synapses," Pharmacopsychiatry, vol. 43, no. 1, pp. S21-S31, 2010.

[22] L. Wang, A. Fontanini, and A. Maffei, "Visual experience modulates spatio-temporal dynamics of circuit activation," Frontiers in Cellular Neuroscience, vol. 5, article 12, 2011.

[23] K. Lamsa, J. H. Heeroma, and D. M. Kullmann, "Hebbian LTP in feed-forward inhibitory interneurons and the temporal fidelity of input discrimination," Nature Neuroscience, vol. 8, no. 7, pp. 916-924, 2005.

[24] A. Semyanov, M. C. Walker, and D. M. Kullmann, "GABA uptake regulates cortical excitability via cell type-specific tonic inhibition," Nature Neuroscience, vol. 6, no. 5, pp. 484490, 2003.

[25] C. J. Wierenga and W. J. Wadman, "Miniature inhibitory postsynaptic currents in CA1 pyramidal neurons after kindling epileptogenesis," Journal of Neurophysiology, vol. 82, no. 3, pp. 1352-1362, 1999.

[26] G. G. Turrigiano and S. B. Nelson, "Hebb and homeostasis in neuronal plasticity," Current Opinion in Neurobiology, vol. 10, no. 3, pp. 358-364, 2000.

[27] G. G. Turrigiano and S. B. Nelson, "Homeostatic plasticity in the developing nervous system," Nature Reviews Neuroscience, vol. 5, no. 2, pp. 97-107, 2004.

[28] G. G. Turrigiano, "Homeostatic plasticity in neuronal networks: the more things change, the more they stay the same," Trends in Neurosciences, vol. 22, no. 5, pp. 221-227, 1999.

[29] M. Esclapez and C. R. Houser, "Up-regulation of GAD65 and GAD67 in remaining hippocampal GABA neurons in a model of temporal lobe epilepsy," Journal of Comparative Neurology, vol. 412, no. 3, pp. 488-505, 1999.

[30] P. E. Garraghty, E. A. LaChica, and J. H. Kaas, "Injuryinduced reorganization of somatosensory cortex is accompanied by reductions in GABA staining," Somatosensory and Motor Research, vol. 8, no. 4, pp. 347-354, 1991.

[31] K. N. Hartman, S. K. Pal, J. Burrone, and V. N. Murthy, "Activity-dependent regulation of inhibitory synaptic transmission in hippocampal neurons," Nature Neuroscience, vol. 9, no. 5, pp. 642-649, 2006.

[32] R. W. Olsen and W. Sieghart, "International Union of Pharmacology. LXX. Subtypes of $\gamma$-aminobutyric acidA receptors: classification on the basis of subunit composition, pharmacology, and function. Update," Pharmacological Reviews, vol. 60, no. 3, pp. 243-260, 2008.

[33] J. S. Coombs, J. C. Eccles, and P. FATT, "The specific ionic conductances and the ionic movements across the motoneuronal membrane that produce the inhibitory post-synaptic potential," The Journal of physiology, vol. 130, no. 2, pp. 326374, 1955.

[34] P. Rudomin and R. F. Schmidt, "Presynaptic inhibition in the vertebrate spinal cord revisited," Experimental Brain Research, vol. 129, no. 1, pp. 1-37, 1999.

[35] G. Stuart, "Voltage-activated sodium channels amplify inhibition in neocortical pyramidal neurons," Nature Neuroscience, vol. 2, no. 2, pp. 144-150, 1999.

[36] Y. Ben-Ari, E. Cherubini, R. Corradetti, and J. L. Gaiarsa, "Giant synaptic potentials in immature rat CA3 hippocampal neurones," Journal of Physiology, vol. 416, pp. 303-325, 1989.

[37] Y. Ben-Ari, J. L. Gaiarsa, R. Tyzio, and R. Khazipov, "GABA: A pioneer transmitter that excites immature neurons and generates primitive oscillations," Physiological Reviews, vol. 87, no. 4, pp. 1215-1284, 2007.

[38] E. Cherubini, J. L. Gaiarsa, and Y. Ben-Ari, "GABA: an excitatory transmitter in early postnatal life," Trends in Neurosciences, vol. 14, no. 12, pp. 515-519, 1991.

[39] R. Tyzio, C. Allene, R. Nardou et al., "Depolarizing actions of GABA in immature neurons depend neither on ketone bodies nor on pyruvate," Journal of Neuroscience, vol. 31, no. 1, pp. 34-45, 2011.

[40] Y. Ben-Ari and G. L. Holmes, "Effects of seizures on developmental processes in the immature brain," Lancet Neurology, vol. 5, no. 12, pp. 1055-1063, 2006.

[41] G. Huberfeld, L. Wittner, S. Clemenceau et al., "Perturbed chloride homeostasis and GABAergic signaling in human temporal lobe epilepsy," Journal of Neuroscience, vol. 27, no. 37, pp. 9866-9873, 2007.

[42] S. Rheims, C. D. Holmgren, G. Chazal et al., "GABA action in immature neocortical neurons directly depends on the availability of ketone bodies," Journal of Neurochemistry, vol. 110, no. 4, pp. 1330-1338, 2009.

[43] K. Kaupmann, K. Huggel, J. Heid et al., "Expression cloning of $\mathrm{GABA}_{\mathrm{B}}$ receptors uncovers similarity to metabotropic glutamate receptors," Nature, vol. 386, no. 6622, pp. 239-246, 1997.

[44] R. Kuner, G. Kohn, S. Grunewald, G. Eisenhardt, A. Bach, and H. C. Kornau, "Role of heteromer formation in $\mathrm{GABA}_{\mathrm{B}}$ receptor function," Science, vol. 283, no. 5398, pp. 74-77, 1999.

[45] N. G. Bowery and D. A. Brown, "The cloning of $G_{A B A}$ receptors," Nature, vol. 386, no. 6622, pp. 223-224, 1997.

[46] U. Misgeld, M. Bijak, and W. Jarolimek, "A physiological role for $\mathrm{GABA}_{\mathrm{B}}$ receptors and the effects of baclofen in the mammalian central nervous system," Progress in Neurobiology, vol. 46, no. 4, pp. 423-462, 1995.

[47] I. Mody, "Distinguishing between $\mathrm{GABA}_{\mathrm{A}}$ receptors responsible for tonic and phasic conductances," Neurochemical Research, vol. 26, no. 8-9, pp. 907-913, 2001.

[48] A. Semyanov, M. C. Walker, D. M. Kullmann, and R. A. Silver, "Tonically active $\mathrm{GABA}_{\mathrm{A}}$ receptors: modulating gain and maintaining the tone," Trends in Neurosciences, vol. 27, no. 5, pp. 262-269, 2004.

[49] N. I. Holter, M. M. Zylla, N. Zuber, C. Bruehl, and A. Draguhn, "Tonic GABAergic control of mouse dentate granule cells during postnatal development," European Journal of Neuroscience, vol. 32, no. 8, pp. 1300-1309, 2010.

[50] M. I. Banks and R. A. Pearce, "Kinetic differences between synaptic and extrasynaptic $\mathrm{GABA}_{\mathrm{A}}$ receptors in CA1 pyramidal cells," Journal of Neuroscience, vol. 20, no. 3, pp. 937-948, 2000.

[51] U. Tossman, G. Jonsson, and U. Ungerstedt, "Regional distribution and extracellular levels of amino acids in rat central nervous system," Acta Physiologica Scandinavica, vol. 127, no. 4, pp. 533-545, 1986.

[52] J. Lerma, A. S. Herranz, and O. Herreras, "In vivo determination of extracellular concentration of amino acids in the rat hippocampus. A method based on brain dialysis and computerized analysis," Brain Research, vol. 384, no. 1, pp. 145-155, 1986.

[53] N. Hájos, Z. Nusser, E. A. Rancz, T. F. Freund, and I. Mody, "Cell type- and synapse-specific variability in synaptic $\mathrm{GABA}_{\mathrm{A}}$ receptor occupancy," European Journal of Neuroscience, vol. 12, no. 3, pp. 810-818, 2000.

[54] W. Hevers and H. Lüddens, "The diversity of $\mathrm{GABA}_{\mathrm{A}}$ receptors: pharmacological and electrophysiological properties of 
$\mathrm{GABA}_{\mathrm{A}}$ channel subtypes," Molecular Neurobiology, vol. 18, no. 1, pp. 35-86, 1998.

[55] M. Bartos, I. Vida, M. Frotscher, J. R. P. Geiger, and P. Jonas, "Rapid signaling at inhibitory synapses in a dentate gyrus interneuron network," Journal of Neuroscience, vol. 21, no. 8, pp. 2687-2698, 2001.

[56] C. J. Price, B. Cauli, E. R. Kovacs et al., "Neurogliaform neurons form a novel inhibitory network in the hippocampal CA1 area," Journal of Neuroscience, vol. 25, no. 29, pp. 67756786, 2005.

[57] M. Capogna, "Neurogliaform cells and other interneurons of stratum lacunosum-moleculare gate entorhinal-hippocampal dialogue," Journal of Physiology, vol. 589, no. 8, pp. 1875$1883,2011$.

[58] S. Oláh, M. Füle, G. Komlósi et al., "Regulation of cortical microcircuits by unitary GABA-mediated volume transmission," Nature, vol. 461, no. 7268, pp. 1278-1281, 2009.

[59] S. M. Jones and M. J. Palmer, "Activation of the tonic $\mathrm{GABA}_{\mathrm{C}}$ receptor current in retinal bipolar cell terminals by nonvesicular GABA release," Journal of Neurophysiology, vol. 102, no. 2, pp. 691-699, 2009.

[60] Y. Wu, W. Wang, A. Díez-Sampedro, and G. B. Richerson, "Nonvesicular inhibitory neurotransmission via reversal of the GABA transporter GAT-1," Neuron, vol. 56, no. 5, pp. 851-865, 2007.

[61] A. Ströhle, E. Romeo, F. Di Michele et al., "GABA ${ }_{\mathrm{A}}$ receptormodulating neuroactive steroid composition in patients with panic disorder before and during paroxetine treatment," American Journal of Psychiatry, vol. 159, no. 1, pp. 145-147, 2002.

[62] J. Maguire and I. Mody, "Steroid hormone fluctuations and $\mathrm{GABA}_{\mathrm{A}}$ R plasticity," Psychoneuroendocrinology, vol. 34, no. 1, pp. S84-S90, 2009.

[63] G. A. Ascoli, L. Alonso-Nanclares, S. A. Anderson et al., "Petilla terminology: nomenclature of features of GABAergic interneurons of the cerebral cortex," Nature Reviews Neuroscience, vol. 9, no. 7, pp. 557-568, 2008.

[64] H. Markram, M. Toledo-Rodriguez, Y. Wang, A. Gupta, G. Silberberg, and $\mathrm{C}$. Wu, "Interneurons of the neocortical inhibitory system,” Nature Reviews Neuroscience, vol. 5, no. 10, pp. 793-807, 2004.

[65] P. Somogyi and T. Klausberger, "Defined types of cortical interneurone structure space and spike timing in the hippocampus," Journal of Physiology, vol. 562, no. 1, pp. 9-26, 2005.

[66] D. Pinault, "A novel single-cell staining procedure performed in vivo under electrophysiological control: morphofunctional features of juxtacellularly labeled thalamic cells and other central neurons with biocytin or Neurobiotin," Journal of Neuroscience Methods, vol. 65, no. 2, pp. 113-136, 1996.

[67] J. J. Tukker, P. Fuentealba, K. Hartwich, P. Somogyi, and T. Klausberger, "Cell type-specific tuning of hippocampal interneuron firing during gamma oscillations in vivo," Journal of Neuroscience, vol. 27, no. 31, pp. 8184-8189, 2007.

[68] X. J. Wang and G. Buzsáki, "Gamma oscillation by synaptic inhibition in a hippocampal interneuronal network model," Journal of Neuroscience, vol. 16, no. 20, pp. 6402-6413, 1996.

[69] R. D. Traub, M. O. Cunningham, T. Gloveli et al., "GABAenhanced collective behavior in neuronal axons underlies persistent gamma-frequency oscillations," Proceedings of the National Academy of Sciences of the United States of America, vol. 100, no. 19, pp. 11047-11052, 2003.
[70] M. A. Whittington, R. D. Traub, N. Kopell, B. Ermentrout, and E. H. Buhl, "Inhibition-based rhythms: experimental and mathematical observations on network dynamics," International Journal of Psychophysiology, vol. 38, no. 3, pp. 315336, 2000.

[71] E. O. Mann and O. Paulsen, "Role of GABAergic inhibition in hippocampal network oscillations," Trends in Neurosciences, vol. 30, no. 7, pp. 343-349, 2007.

[72] E. O. Mann, J. M. Suckling, N. Hajos, S. A. Greenfield, and O. Paulsen, "Perisomatic feedback inhibition underlies cholinergically induced fast network oscillations in the rat hippocampus in vitro," Neuron, vol. 45, no. 1, pp. 105-117, 2005.

[73] S. K. Towers, F. E. N. LeBeau, T. Gloveli, R. D. Traub, M. A. Whittington, and E. H. Buhl, "Fast network oscillations in the rat dentate gyrus in vitro," Journal of Neurophysiology, vol. 87, no. 2, pp. 1165-1168, 2002.

[74] M. Blatow, A. Rozov, I. Katona et al., "A novel network of multipolar bursting interneurons generates theta frequency oscillations in neocortex," Neuron, vol. 38, no. 5, pp. 805-817, 2003.

[75] M. Bartos, I. Vida, M. Frotscher et al., "Fast synaptic inhibition promotes synchronized gamma oscillations in hippocampal interneuron networks," Proceedings of the National Academy of Sciences of the United States of America, vol. 99, no. 20, pp. 13222-13227, 2002.

[76] S. R. Cobb, E. H. Buhl, K. Halasy, O. Paulsen, and P. Somogyl, "Synchronization of neuronal activity in hippocampus by individual GABAergic interneurons," Nature, vol. 378, no. 6552, pp. 75-78, 1995.

[77] E. A. Barnard, P. Skolnick, R. W. Olsen et al., "International union of pharmacology. XV. Subtypes of $\gamma$-aminobutyric $\mathrm{acid}_{\mathrm{A}}$ receptors: classification on the basis of subunit structure and receptor function," Pharmacological Reviews, vol. 50, no. 2, pp. 291-313, 1998.

[78] A. K. Mehta and M. K. Ticku, "An update on $\mathrm{GABA}_{\mathrm{A}}$ receptors," Brain Research Reviews, vol. 29, no. 2-3, pp. 196217, 1999.

[79] I. Mody and R. A. Pearce, "Diversity of inhibitory neurotransmission through $\mathrm{GABA}_{\mathrm{A}}$ receptors," Trends in Neurosciences, vol. 27, no. 9, pp. 569-575, 2004.

[80] C. Essrich, M. Lorez, J. A. Benson, J. M. Fritschy, and B. Lüscher, "Postsynaptic clustering of major $\mathrm{GABA}_{\mathrm{A}}$ receptor subtypes requires the $\gamma 2$ subunit and gephyrin," Nature Neuroscience, vol. 1, no. 7, pp. 563-571, 1998.

[81] J. T. Kittler, K. McAinsh, and S. J. Moss, "Mechanisms of $\mathrm{GABA}_{\mathrm{A}}$ receptor assembly and trafficking: implications for the modulation of inhibitory neurotransmission," Molecular Neurobiology, vol. 26, no. 2-3, pp. 251-268, 2002.

[82] M. Giustetto, J. Kirsch, J. M. Fritschy, D. Cantino, and M. Sassoè-Pognetto, "Localization of the clustering protein gephyrin at GABAergic synapses in the main olfactory bulb of the rat," Journal of Comparative Neurology, vol. 395, no. 2, pp. 231-244, 1998.

[83] M. Kneussel and H. Betz, "Clustering of inhibitory neurotransmitter receptors at developing postsynaptic sites: the membrane activation model," Trends in Neurosciences, vol. 23, no. 9, pp. 429-435, 2000.

[84] J. W. Mozrzymas, E. D. Zarmowska, M. Pytel, and K. Mercik, "Modulation of $\mathrm{GABA}_{\mathrm{A}}$ receptors by hydrogen ions reveals synaptic GABA transient and a crucial role of the desensitization process," Journal of Neuroscience, vol. 23, no. 22, pp. 7981-7992, 2003. 
[85] A. Barberis, E. M. Petrini, and E. Cherubini, "Presynaptic source of quantal size variability at GABAergic synapses in rat hippocampal neurons in culture," European Journal of Neuroscience, vol. 20, no. 7, pp. 1803-1810, 2004.

[86] J. Glykys and I. Mody, "The main source of ambient GABA responsible for tonic inhibition in the mouse hippocampus," Journal of Physiology, vol. 582, no. 3, pp. 1163-1178, 2007.

[87] J. C. Eccles, R. F. Schmidt, and W. D. Willis, "Presynaptic inhibition of the spinal monosynaptic reflex pathway," The Journal of physiology, vol. 161, pp. 282-297, 1962.

[88] H. Alle and J. R. P. Geiger, "GABAergic spill-over transmission onto hippocampal mossy fiber boutons," Journal of Neuroscience, vol. 27, no. 4, pp. 942-950, 2007.

[89] S. F. Stasheff, D. D. Mott, and W. A. Wilson, "Axon terminal hyperexcitability associated with epileptogenesis in vitro. II. Pharmacological regulation by NMDA and $\mathrm{GABA}_{\mathrm{A}}$ receptors," Journal of Neurophysiology, vol. 70, no. 3, pp. 976984, 1993.

[90] B. M. Stell, P. Rostaing, A. Triller, and A. Marty, "Activation of presynaptic $\mathrm{GABA}_{\mathrm{A}}$ receptors induces glutamate release from parallel fiber synapses," Journal of Neuroscience, vol. 27, no. 34, pp. 9022-9031, 2007.

[91] S. L. Hansen, B. Fjalland, and M. B. Jackson, "Modulation of $\mathrm{GABA}_{\mathrm{A}}$ receptors and neuropeptide secretion by the neurosteroid allopregnanolone in posterior and intermediate pituitary," Pharmacology and Toxicology, vol. 93, no. 2, pp. 91-97, 2003.

[92] A. Draguhn, N. Axmacher, and S. Kolbaev, "Presynaptic ionotropic GABA receptors," Results and Problems in Cell Differentiation, vol. 44, pp. 69-85, 2007.

[93] D. M. Kullmann, "Spillover and synaptic cross talk mediated by glutamate and GABA in the mammalian brain," Progress in Brain Research, vol. 125, pp. 339-351, 2000.

[94] M. Scanziani, "GABA spillover activates postsynaptic $\mathrm{GABA}_{B}$ receptors to control rhythmic hippocampal activity," Neuron, vol. 25, no. 3, pp. 673-681, 2000.

[95] K. E. Vogt and R. A. Nicoll, "Glutamate and $\gamma$-aminobutyric acid mediate a heterosynaptic depression at mossy fiber synapses in the hippocampus," Proceedings of the National Academy of Sciences of the United States of America, vol. 96, no. 3, pp. 1118-1122, 1999.

[96] J. S. Isaacson, J. M. Solis, and R. A. Nicoll, "Local and diffuse synaptic actions of GABA in the hippocampus," Neuron, vol. 10, no. 2, pp. 165-175, 1993.

[97] Y. Wang, F. B. Neubauer, H. R. Lüscher, and K. Thurley, " $\mathrm{GABA}_{\mathrm{B}}$ receptor-dependent modulation of network activity in the rat prefrontal cortex in vitro," European Journal of Neuroscience, vol. 31, no. 9, pp. 1582-1594, 2010.

[98] J. N. Cammack, S. V. Rakhilin, and E. A. Schwartz, "A GABA transporter operates asymmetrically and with variable stoichiometry," Neuron, vol. 13, no. 4, pp. 949-960, 1994.

[99] J. L. Corey, J. Guastella, N. Davidson, and H. A. Lester, "GABA uptake and release by a mammalian cell line stably expressing a cloned rat brain GABA transporter," Molecular membrane biology, vol. 11, no. 1, pp. 23-30, 1994.

[100] D. Attwell, B. Barbour, and M. Szatkowski, "Nonvesicular release of neurotransmitter," Neuron, vol. 11, no. 3, pp. 401407, 1993.

[101] M. J. During, K. M. Ryder, and D. D. Spencer, "Hippocampal GABA transporter function in temporal-lobe epilepsy," Nature, vol. 376, no. 6536, pp. 174-177, 1995.

[102] A. Yamauchi, S. Uchida, H. M. Kwon et al., "Cloning of a $\mathrm{Na}^{+}$- and $\mathrm{Cl}^{-}$-dependent betaine transporter that is regulated by hypertonicity," Journal of Biological Chemistry, vol. 267, no. 1, pp. 649-652, 1992.

[103] J. Guastella, N. Nelson, H. Nelson et al., "Cloning and expression of a rat brain GABA transporter," Science, vol. 249, no. 4974, pp. 1303-1306, 1990.

[104] B. I. Kanner and A. Bendahan, "Two pharmacologically distinct sodium- and chloride-coupled high-affinity $\gamma$ aminobutyric acid transporters are present in plasma membrane vesicles and reconstituted preparations from rat brain," Proceedings of the National Academy of Sciences of the United States of America, vol. 87, no. 7, pp. 2550-2554, 1990.

[105] Q. -R. Liu, B. Lopez-Corcuera, S. Mandiyan, H. Nelson, and N. Nelson, "Molecular characterization of four pharmacologically distinct gamma-aminobutyric acid transporters in mouse brain," Journal of Biological Chemistry, vol. 268, no. 3, pp. 2106-2112, 1993.

[106] L. A. Borden, K. E. Smith, P. R. Hartig, T. A. Branchek, and R. L. Weinshank, "Molecular heterogeneity of the $\gamma$ aminobutyric acid (GABA) transport system. Cloning of two novel high affinity GABA transporters from rat brain," Journal of Biological Chemistry, vol. 267, no. 29, pp. 2109821104, 1992.

[107] A. Schousboe and H. S. Waagepetersen, "GABA: homeostatic and pharmacological aspects," Progress in Brain Research, vol. 160, pp. 9-19, 2007.

[108] F. Conti, M. Melone, S. De Biasi, A. Minelli, N. C. Brecha, and A. Ducati, "Neuronal and glial localization of GAT-1, a highaffinity $\gamma$-aminobutyric acid plasma membrane transporter, in human cerebral cortex: with a note on its distribution in monkey cortex," Journal of Comparative Neurology, vol. 396, no. 1, pp. 51-63, 1998.

[109] A. Minelli, S. DeBiasi, N. C. Brecha, L. V. Zuccarello, and F. Conti, "GAT-3, a high-affinity GABA plasma membrane transporter, is localized to astrocytic processes, and it is not confined to the vicinity of GABAergic synapses in the cerebral cortex," Journal of Neuroscience, vol. 16, no. 19, pp. 62556264, 1996.

[110] C. E. Ribak, W. M. Y. Tong, and N. C. Brecha, "GABA plasma membrane transporters, GAT-1 and GAT-3, display different distributions in the rat hippocampus," Journal of Comparative Neurology, vol. 367, no. 4, pp. 595-606, 1996.

[111] J. D. Rothstein, L. Martin, A. I. Levey et al., "Localization of neuronal and glial glutamate transporters," Neuron, vol. 13, no. 3, pp. 713-725, 1994.

[112] F. Conti, S. DeBiasi, A. Minelli, J. D. Rothstein, and M. Melone, "EAAC1, a high-affinity glutamate transporter, is localized to astrocytes and gabaergic neurons besides pyramidal cells in the rat cerebral cortex," Cerebral Cortex, vol. 8, no. 2, pp. 108-116, 1998.

[113] Y. He, W. G. M. Janssen, J. D. Rothstein, and J. H. Morrison, "Differential synaptic localization of the glutamate transporter EAAC1 and glutamate receptor subunit GluR2 in the rat hippocampus," Journal of Comparative Neurology, vol. 418, no. 3, pp. 255-269, 2000.

[114] O. M. Larsson, J. Drejer, E. Kvamme, G. Svenneby, L. Hertz, and A. Schousboe, "Ontogenetic development of glutamate and GABA metabolizing enzymes in cultured cerebral cortex interneurons and in cerebral cortex in vivo," International Journal of Developmental Neuroscience, vol. 3, no. 2, pp. 177185, 1985.

[115] M. Melone, F. Quagliano, P. Barbaresi, H. Varoqui, J. D. Erickson, and F. Conti, "Localization of the glutamine transporter SNAT1 in rat cerebral cortex and neighboring 
structures, with a note on its localization in human cortex," Cerebral Cortex, vol. 14, no. 5, pp. 562-574, 2004.

[116] M. G. Erlander and A. J. Tobin, "The structural and functional heterogeneity of glutamic acid decarboxylase: a review," Neurochemical Research, vol. 16, no. 3, pp. 215-226, 1991.

[117] M. Esclapez, N. J. K. Tillakaratne, D. L. Kaufman, A. J. Tobin, and C. R. Houser, "Comparative localization of two forms of glutamic acid decarboxylase and their mRNAs in rat brain supports the concept of functional differences between the forms," Journal of Neuroscience, vol. 14, no. 3, pp. 1834-1855, 1994.

[118] H. Jin, H. Wu, G. Osterhaus et al., "Demonstration of functional coupling between $\gamma$-aminobutyric acid (GABA) synthesis and vesicular GABA transport into synaptic vesicles," Proceedings of the National Academy of Sciences of the United States of America, vol. 100, no. 7, pp. 4293-4298, 2003.

[119] I. Jacobson, M. Sandberg, and A. Hamberger, "Mass transfer in brain dialysis devices-a new method for the estimation of extracellular amino acids concentration," Journal of Neuroscience Methods, vol. 15, no. 3, pp. 263-268, 1985.

[120] K. Kanamori and B. D. Ross, "Quantitative determination of extracellular glutamine concentration in rat brain, and its elevation in vivo by system A transport inhibitor, $\alpha$ (methylamino)isobutyrate," Journal of Neurochemistry, vol. 90, no. 1, pp. 203-210, 2004.

[121] L. K. Bak, A. Schousboe, and H. S. Waagepetersen, "The glutamate/GABA-glutamine cycle: aspects of transport, neurotransmitter homeostasis and ammonia transfer," Journal of Neurochemistry, vol. 98, no. 3, pp. 641-653, 2006.

[122] S. Bröer and N. Brookes, "Transfer of glutamine between astrocytes and neurons," Journal of Neurochemistry, vol. 77, no. 3, pp. 705-719, 2001.

[123] I. M. González-González, B. Cubelos, C. Giménez, and F. Zafra, "Immunohistochemical localization of the amino acid transporter SNAT2 in the rat brain," Neuroscience, vol. 130, no. 1, pp. 61-73, 2005.

[124] S. L. Liang, G. C. Carlson, and D. A. Coulter, "Dynamic regulation of synaptic GABA release by the glutamate-glutamine cycle in hippocampal area CA1," Journal of Neuroscience, vol. 26, no. 33, pp. 8537-8548, 2006.

[125] M. N. Fricke, D. M. Jones-Davis, and G. C. Mathews, "Glutamine uptake by System A transporters maintains neurotransmitter GABA synthesis and inhibitory synaptic transmission," Journal of Neurochemistry, vol. 102, no. 6, pp. 1895 1904, 2007.

[126] A. S. Bryant, B. Li, M. P. Beenhakker, and J. R. Huguenard, "Maintenance of thalamic epileptiform activity depends on the astrocytic glutamate-glutamine cycle," Journal of Neurophysiology, vol. 102, no. 5, pp. 2880-2888, 2009.

[127] H. Tani, A. E. Bandrowski, I. Parada et al., "Modulation of epileptiform activity by glutamine and System A transport in a model of post-traumatic epilepsy," Neurobiology of Disease, vol. 25, no. 2, pp. 230-238, 2007.

[128] M. N. Brown and G. C. Mathews, "Activity- and age-dependent modulation of GABAergic neurotransmission by System A-mediated glutamine uptake," Journal of Neurochemistry, vol. 114, no. 3, pp. 909-920, 2010.

[129] G. Ahnert-Hilger and R. Jahn, "CLC-3 spices up GABAergic synaptic vesicles," Nature Neuroscience, vol. 14, no. 4, pp. 405-407, 2011.

[130] C. C. Hsu, C. Thomas, W. Chen et al., "Role of synaptic vesicle proton gradient and protein phosphorylation on ATP-mediated activation of membrane-associated brain glutamate decarboxylase," Journal of Biological Chemistry, vol. 274, no. 34, pp. 24366-24371, 1999.

[131] V. Riazanski, L. V. Deriy, P. D. Shevchenko, B. Le, E. A. Gomez, and D. J. Nelson, "Presynaptic CLC-3 determines quantal size of inhibitory transmission in the hippocampus," Nature Neuroscience, vol. 14, no. 4, pp. 487-494, 2011.

[132] J. D. Erickson, S. De Gois, H. Varoqui, M. K. H. Schafer, and E. Weihe, "Activity-dependent regulation of vesicular glutamate and GABA transporters: a means to scale quantal size," Neurochemistry International, vol. 48, no. 6-7, pp. 643649, 2006.

[133] J. W. Hell, L. Edelmann, J. Hartinger, and R. Jahn, "Functional reconstitution of the $\gamma$-aminobutyric acid transporter from synaptic vesicles using artificial ion gradients," Biochemistry, vol. 30, no. 51, pp. 11795-11800, 1991.

[134] P. Jonas, J. Bischofberger, and J. Sandkühler, "Corelease of two fast neurotransmitters at a central synapse," Science, vol. 281, no. 5375, pp. 419-424, 1998.

[135] R. H. Edwards, "The neurotransmitter cycle and quantal size," Neuron, vol. 55, no. 6, pp. 835-858, 2007.

[136] S. Takamori, M. Holt, K. Stenius et al., "Molecular anatomy of a trafficking organelle," Cell, vol. 127, no. 4, pp. 831-846, 2006.

[137] J. Williams, "How does a vesicle know it is full?" Neuron, vol. 18, no. 5, pp. 683-686, 1997.

[138] M. J. Jung, B. Lippert, and B. W. Metcalf, "The effect of 4 amino hex 5 ynoic acid ( $\gamma$ acetylenic GABA, $\gamma$ ethynyl GABA) a catalytic inhibitor of GABA transaminase, on brain GABA metabolism in vivo," Journal of Neurochemistry, vol. 28, no. 4, pp. 717-723, 1977.

[139] I. Schousboe, B. Bro, and A. Schousboe, "Intramitochondrial localization of the 4 aminobutyrate 2 oxoglutarate transaminase from ox brain," Biochemical Journal, vol. 162, no. 2, pp. 303-307, 1977.

[140] P. Kugler, "In situ measurements of enzyme activities in the brain," Histochemical Journal, vol. 25, no. 5, pp. 329-338, 1993.

[141] J. A. Eckstein, G. M. Ammerman, J. M. Reveles, and B. L. Ackermann, "Analysis of glutamine, glutamate, pyroglutamate, and GABA in cerebrospinal fluid using ion pairing HPLC with positive electrospray LC/MS/MS," Journal of Neuroscience Methods, vol. 171, no. 2, pp. 190-196, 2008.

[142] P. M. Burger, E. Mehl, P. L. Cameron et al., "Synaptic vesicles immunoisolated from rat cerebral cortex contain high levels of glutamate," Neuron, vol. 3, no. 6, pp. 715-720, 1989.

[143] A. Barberis, E. M. Petrini, and J. W. Mozrzymas, "Impact of synaptic neurotransmitter concentration time course on the kinetics and pharmacological modulation of inhibitory synaptic currents," Frontiers in Cellular Neuroscience, vol. 5, article 6, 2011.

[144] J. W. Mozrzymas, A. Barberis, K. Michalak, and E. Cherubini, "Chlorpromazine inhibits miniature GABAergic currents by reducing the binding and by increasing the unbinding rate of $\mathrm{GABA}_{\mathrm{A}}$ receptors," Journal of Neuroscience, vol. 19, no. 7, pp. 2474-2488, 1999.

[145] M. V. Jones and G. L. Westbrook, "Desensitized states prolong $\mathrm{GABA}_{\mathrm{A}}$ channel responses to brief agonist pulses," Neuron, vol. 15, no. 1, pp. 181-191, 1995.

[146] D. J. Maconochie, J. M. Zempel, and J. H. Steinbach, "How quickly can $\mathrm{GABA}_{\mathrm{A}}$ receptors open?” Neuron, vol. 12, no. 1, pp. 61-71, 1994.

[147] D. Perrais and N. Ropert, "Effect of zolpidem on miniature IPSCs and occupancy of postsynaptic $\mathrm{GABA}_{\mathrm{A}}$ receptors in 
central synapses," Journal of Neuroscience, vol. 19, no. 2, pp. 578-588, 1999.

[148] G. Buzsáki, D. L. Buhl, K. D. Harris, J. Csicsvari, B. Czéh, and A. Morozov, "Hippocampal network patterns of activity in the mouse," Neuroscience, vol. 116, no. 1, pp. 201-211, 2003.

[149] H. Berger, "Über das Elektrenkephalogramm des Menschen," Archiv für Psychiatrie und Nervenkrankheiten, vol. 87, no. 1, pp. 527-570, 1929.

[150] J. Csicsvari, H. Hirase, A. Czurkó, A. Mamiya, and G. Buzsáki, "Oscillatory coupling of hippocampal pyramidal cells and interneurons in the behaving rat," Journal of Neuroscience, vol. 19, no. 1, pp. 274-287, 1999.

[151] F. Bähner, E. K. Weiss, G. Birke et al., "Cellular correlate of assembly formation in oscillating hippocampal networks in vitro," Proceedings of the National Academy of Sciences of the United States of America, vol. 108, no. 35, pp. E607-E616, 2011.

[152] L. A. Tremere and R. Pinaud, "Incongruent restoration of inhibitory transmission and general metabolic activity during reorganization of somatosensory cortex," International Journal of Neuroscience, vol. 115, no. 7, pp. 1003-1015, 2005.

[153] M. Costa-Mattioli, W. S. Sossin, E. Klann, and N. Sonenberg, "Translational control of long-lasting synaptic plasticity and memory," Neuron, vol. 61, no. 1, pp. 10-26, 2009.

[154] Y. Lu, K. Christian, and B. Lu, "BDNF: a key regulator for protein synthesis-dependent LTP and long-term memory?" Neurobiology of Learning and Memory, vol. 89, no. 3, pp. 312323, 2008.

[155] C. P. Bengtson, H. E. Freitag, J. M. Weislogel, and H. Bading, "Nuclear calcium sensors reveal that repetition of trains of synaptic stimuli boosts nuclear calcium signaling in CA1 pyramidal neurons," Biophysical Journal, vol. 99, no. 12, pp. 4066-4077, 2010.

[156] J. M. Frade and Y. A. Barde, "Nerve growth factor: two receptors, multiple functions," BioEssays, vol. 20, no. 2, pp. 137-145, 1998.

[157] R. Gutiérrez, "The dual glutamatergic-GABAergic phenotype of hippocampal granule cells," Trends in Neurosciences, vol. 28, no. 6, pp. 297-303, 2005.

[158] G. Gómez-Lira, M. Lamas, H. Romo-Parra, and R. Gutiérrez, "Programmed and induced phenotype of the hippocampal granule cells," Journal of Neuroscience, vol. 25, no. 30, pp. 6939-6946, 2005.

[159] M. C. Walker, A. Ruiz, and D. M. Kullmann, "Do mossy fibers release GABA?” Epilepsia, vol. 43, no. 5, pp. 196-202, 2002.

[160] J. R. Gomes, A. C. Lobo, C. V. Melo et al., "Cleavage of the vesicular GABA transporter under excitotoxic conditions is followed by accumulation of the truncated transporter in nonsynaptic sites," Journal of Neuroscience, vol. 31, no. 12, pp. 4622-4635, 2011.

[161] M. Lamas, G. Gómez-Lira, and R. Gutiérrez, "Vesicular GABA transporter mRNA expression in the dentate gyrus and in mossy fiber synaptosomes," Molecular Brain Research, vol. 93, no. 2, pp. 209-214, 2001.

[162] J. P. Sepkuty, A. S. Cohen, C. Eccles et al., "A neuronal glutamate transporter contributes to neurotransmitter GABA synthesis and epilepsy," Journal of Neuroscience, vol. 22, no. 15, pp. 6372-6379, 2002.

[163] B. Hinz, A. Becher, D. Mitter et al., "Activity-dependent changes of the presynaptic synaptophysin-synaptobrevin complex in adult rat brain," European Journal of Cell Biology, vol. 80, no. 10, pp. 615-619, 2001.
[164] G. C. Mathews and J. S. Diamond, "Neuronal glutamate uptake contributes to GABA synthesis and inhibitory synaptic strength," Journal of Neuroscience, vol. 23, no. 6, pp. 2040 2048, 2003.

[165] K. Hartmann, C. Bruehl, T. Golovko, and A. Draguhn, "Fast homeostatic plasticity of inhibition via activity-dependent vesicular filling," PLoS One, vol. 3, no. 8, Article ID e2979, 2008.

[166] K. Kirmse, A. Dvorzhak, S. Kirischuk, and R. Grantyn, "GABA transporter 1 tunes GABAergic synaptic transmission at output neurons of the mouse neostriatum," Journal of Physiology, vol. 586, no. 23, pp. 5665-5678, 2008.

[167] A. Draguhn and U. Heinemann, "Different mechanisms regulate IPSC kinetics in early postnatal and juvenile hippocampal granule cells," Journal of Neurophysiology, vol. 76, no. 6, pp. 3983-3993, 1996.

[168] S. Krause and W. Schwarz, "Identification and selective inhibition of the channel mode of the neuronal GABA transporter 1," Molecular Pharmacology, vol. 68, no. 6, pp. 1728-1735, 2005.

[169] L. Gram, O. M. Larsson, A. H. Johnsen, and A. Schousboe, "Effects of valproate, vigabatrin and aminooxyacetic acid on release of endogenous and exogenous GABA from cultured neurons," Epilepsy Research, vol. 2, no. 2, pp. 87-95, 1988.

[170] W. Loscher, R. Jackel, and F. Muller, "Anticonvulsant and proconvulsant effects of inhibitors of GABA degradation in the amygdala-kindling model," European Journal of Pharmacology, vol. 163, no. 1, pp. 1-14, 1989.

[171] M. Bialer, S. I. Johannessen, H. J. Kupferberg, R. H. Levy, P. Loiseau, and E. Perucca, "Progress report on new antiepileptic drugs: a summary of The Fourth Eilat Conference (EILAT IV)," Epilepsy Research, vol. 34, no. 1, pp. 1-41, 1999.

[172] J. A. Cramer, R. Fisher, E. Ben-Menachem, J. French, and R. H. Mattson, "New antiepileptic drugs: comparison of key clinical trials," Epilepsia, vol. 40, no. 5, pp. 590-600, 1999.

[173] D. Engel, I. Pahner, K. Schulze et al., "Plasticity of rat central inhibitory synapses through GABA metabolism," Journal of Physiology, vol. 535, no. 2, pp. 473-482, 2001.

[174] N. Axmacher and A. Draguhn, "Inhibition of GABA release by presynaptic ionotropic GABA receptors in hippocampal CA3," NeuroReport, vol. 15, no. 2, pp. 329-334, 2004.

[175] W. H. Butler, G. P. Ford, and J. W. Newberne, "A study of the effects of vigabatrin on the central nervous system and retina of Sprague Dawley and Lister-Hooded rats," Toxicologic Pathology, vol. 15, no. 2, pp. 143-148, 1987.

[176] A. Schousboe, G. Svenneby, and L. Hertz, "Uptake and metabolism of glutamate in astrocytes cultured from dissociated mouse brain hemispheres," Journal of Neurochemistry, vol. 29, no. 6, pp. 999-1005, 1977. 

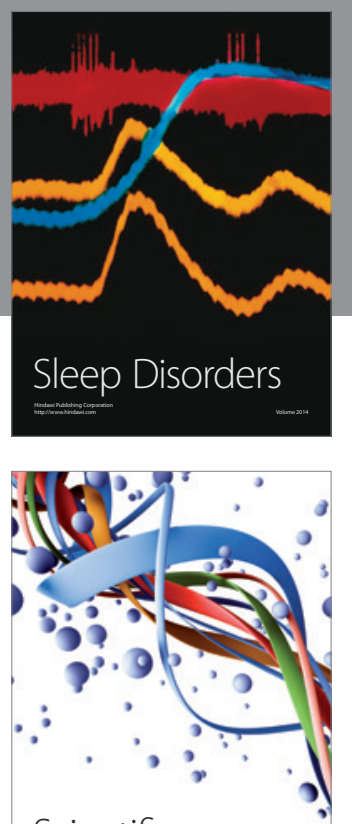

Scientifica
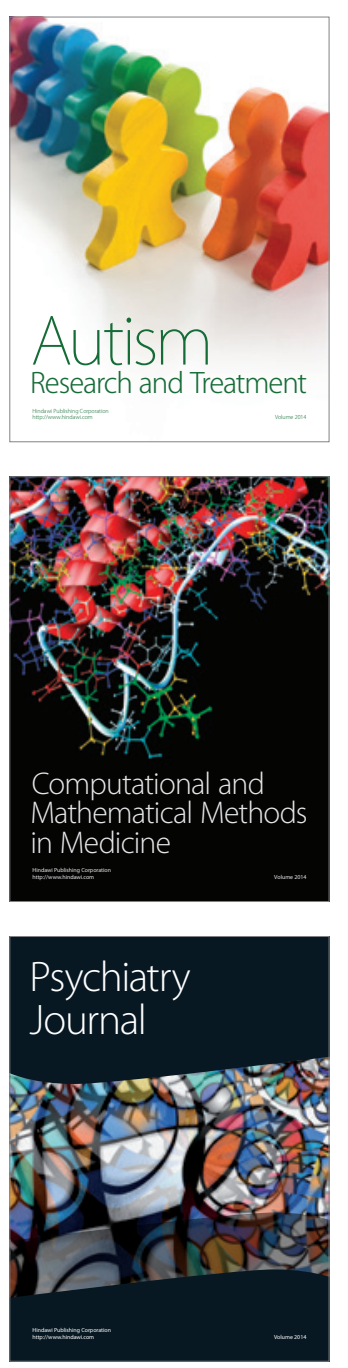
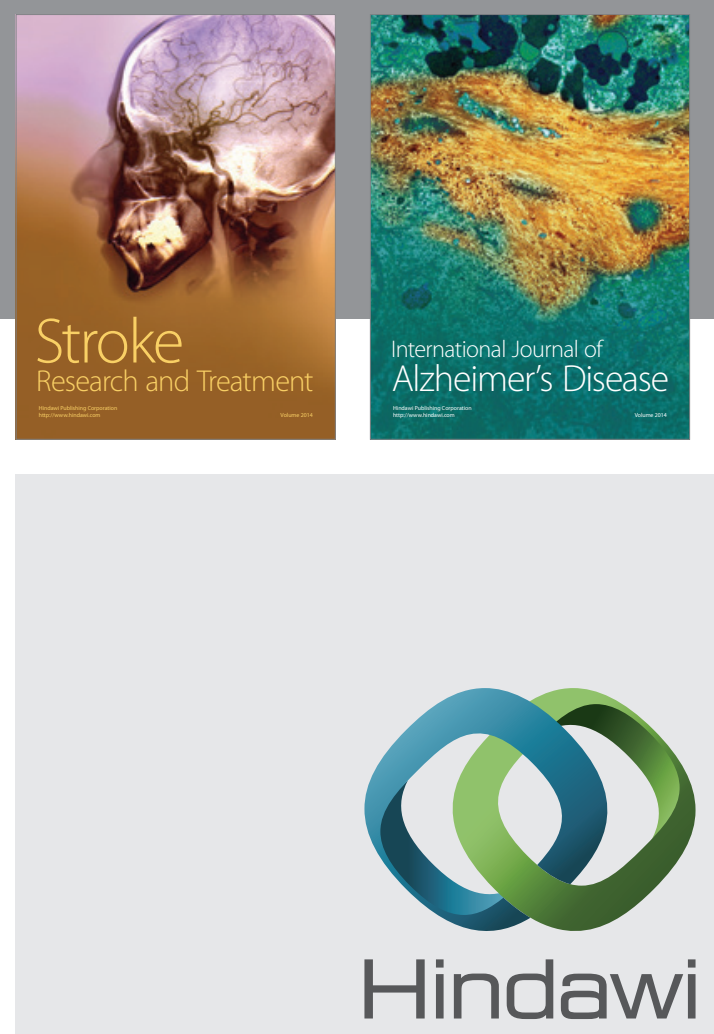

Submit your manuscripts at

http://www.hindawi.com
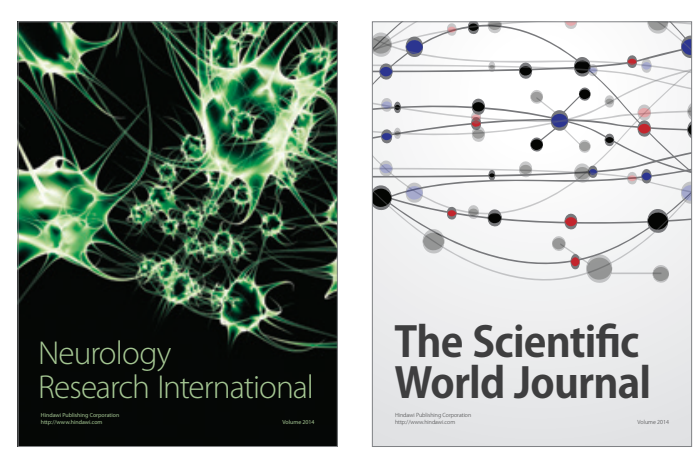

The Scientific World Journal

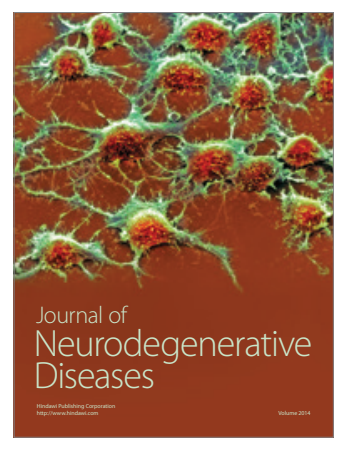

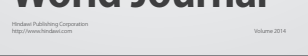

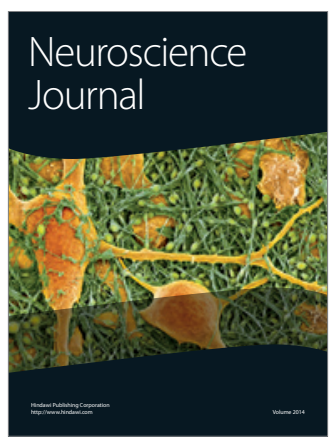

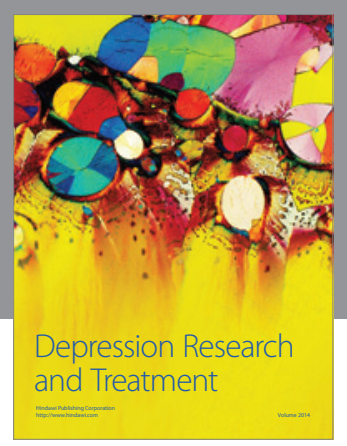
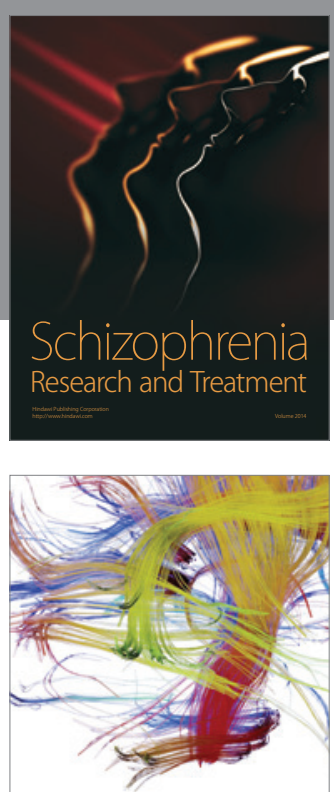

Brain Science

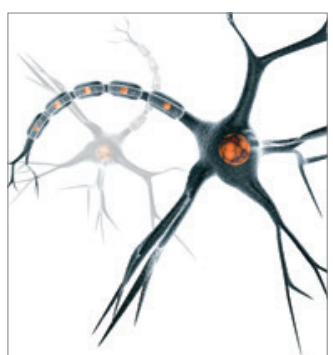

Neural Plasticity
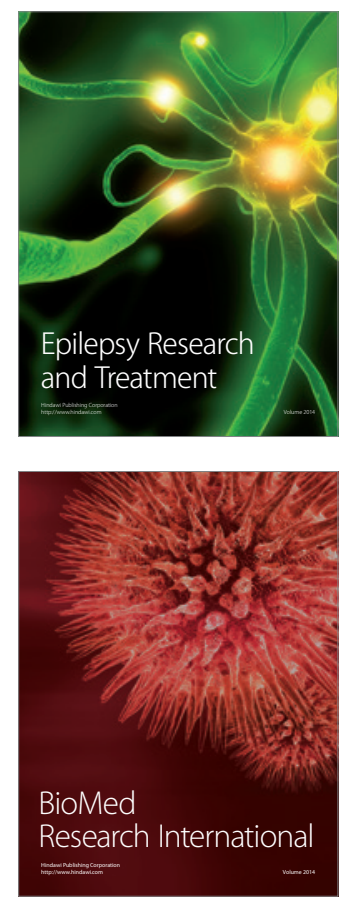

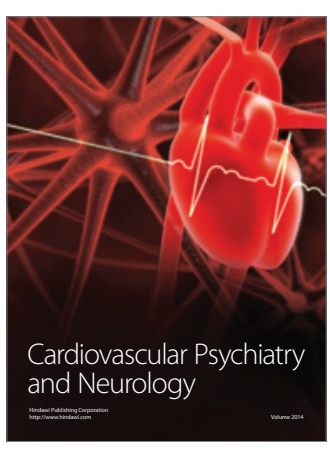

Parkinson's

Disease
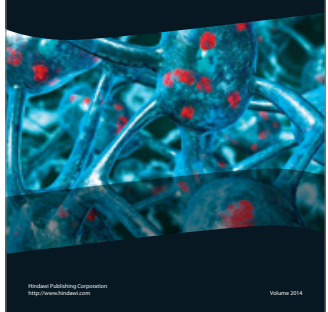